\section{Adrenal extramedullary hematopoiesis associated with $\beta$-thalassemia major}

\section{Bijan Keikhaei, Ahmad Soltani Shirazi, Mahboob Mohammad Pour}

Ahvaz Jundishapur of Medical Sciences, Research Center for Thalassemia and Hemoglobinopathy, Ahvaz, Iran

\section{Abstract}

The presence of apparently normal hematopoietic tissue outside of bone marrow cavity is defined as extramedullary hematopoiesis (EMH). EMH is a rare complication in thalassemia major (TM) and adrenal gland as well. This report describes a case of adrenal EMH in a 26-year-old man with $\beta$-TM. He has been transfused with regular blood transfusion since 9 months. During the routine physical examination he was incidentally found to have a hypoechoic mass at his abdominal ultrasonography. Abdominal computed tomography scan revealed a right well-defined suprarenal mass $7.7 \times 7.3 \times 5.8 \mathrm{~cm}$ in size. The diagnosis of EMH was confirmed with ultrasonographic-guided fine needle biopsy. Treatment options which include intensified regular blood transfusion and hydroxyurea have been started.

\section{Introduction}

Extramedullary hematopoiesis (EMH) is a well-known physiologic or pathologic compensatory mechanism that occurs because of inequality functions between bone marrow supply and circulatory blood demands ${ }^{1}$ EMH is seen in chronic hemolytic diseases such as thalassemia, sickle cell disease, hereditary spherocytosis and in hematologic diseases including myelofibrosis and polycythemia Vera. ${ }^{1-6}$ Although EMH occurs most commonly in the reticuloendothelial system, it may also be seen in organs, such as the pleura, lungs, gastrointestinal tract, breast, skin, brain, kidneys, and adrenal glands. ${ }^{7}$ Paraspinal involvement is expected to need more attention due to the associated morbidity secondary to spinal cord compression. ${ }^{1,2} \mathrm{EMH}$, in a rare condition as in our patient, can be presented as a solitary mass and may pose a diagnostic dilemma. ${ }^{8}$

\section{Case Report}

This report describes a case of 26 years old man with Iranian ethnicity who accidentally was found to have a supra renal mass. He was diagnosed as a case of thalassemia major at the age of 9 months when he presented with a hemoglobin level of $5.5 \mathrm{~g} / \mathrm{dL}$. Throughout his life, he has had a pre-transfusion hemoglobin level of 6-8 $\mathrm{g} / \mathrm{dL}$ with regular blood transfusion. Physical examination revealed a man with a height of $150 \mathrm{~cm}$, head circumference: $59 \mathrm{~cm}$, weight $38 \mathrm{~kg}$ and sex maturity rate of three. He has a characteristic thalassemic facies with pallor and icterus. On physical examination, he was found to have liver and spleen size of 15 and $13 \mathrm{~cm}$ below costal margin respectively. Supra renal mass was not detected on physical examination. Laboratory findings are: hemoglobin $7.2 \mathrm{~g} / \mathrm{dL}, \mathrm{WBC}$ count $4.6 \times 10^{9} / \mathrm{L}$ platelet count $215 \times 10^{9} / \mathrm{L}$, mean corpuscular volume $72.1 \mathrm{fl}$, mean corpuscular hemoglobin $24.6 \mathrm{pg}$. Biochemical investigations were: serum bilirubin - $3.8 \mathrm{mg} / \mathrm{dL}$ (unconjugated bilirubin - $2.8 \mathrm{mg} / \mathrm{dL}$ ), blood urea $25 \mathrm{mg} / \mathrm{dL}$, serum creatinine $0.6 \mathrm{mg} / \mathrm{dL}$, serum calcium $8.2 \mathrm{mg} / \mathrm{dL}$, serum phosphorous $6.6 \mathrm{mg} / \mathrm{dL}$, fasting blood sugar $105 \mathrm{mg} / \mathrm{dL}$, fasting serum cortisol level $14.5 \mathrm{mcg} / \mathrm{dL}$, alanine aminotransferase $51 \mathrm{IU} / \mathrm{dL}$, aspartate aminotransferase $70 \mathrm{IU} / \mathrm{dL}$, serum ferritin 2600 $\mathrm{ng} / \mathrm{mL}$. Tests for hepatitis $\mathrm{C}$ virus and HIV antibodies and serum HBsAg were negative. Abdominal sonography showed huge hepatosplenomegaly and a well-defined right suprarenal solid mass in size of $7.7 \times 7.3 \times 5.8$ $\mathrm{cm}$. Computed tomography (CT) scan of the abdomen (Figure 1) revealed a right suprarenal mass. He was initially admitted to our hospital because of a presumptive diagnosis of malignancy that was suggested by a Sonographist. The appearance of the mass along with the known underlying condition was strongly suggestive of EMH. The definite diagnosis was established with fine needle biopsy. Figure 2 depicted the patient's histopathology that is identical to an active hematopoiesis.

The patient was planned to improve his treatment in other to keep his pre-transfusion hemoglobin level above $10 \mathrm{~g} / \mathrm{dL}$. He was also advised to use hydroxyurea, a gamma inducer drug, for more suppression of ineffective erythropoiesis.

\section{Discussion}

Extramedullary hematopoiesis is the formation and progression of blood cells outside of the bone marrow cavity, in sites other than the long bones such as pelvis, spine and sternum. EMH represents a compensatory response to longstanding hypoxia that produced with chronic anemia. EMH intends to mimic a normal bone marrow. It occurs most commonly in
Correspondence: Bijan Keikhaei, Ahvaz Jundishapur of Medical Sciences, Research Center for Thalassemia and Hemoglobinopathy, Ahvaz, Iran. E-mail: keikhaeib@yahoo.com

Key words: extramedullary hematopoiesis, thalassemia major, adrenal gland.

Acknowledgments: the authors thank Mrs Shaneh, Pour Atiyeh and Shafa laboratory staff for technical assistance.

Conflict of interests: the authors declare no potential conflict of interests.

Received for publication: 2 January 2012.

Revision received: 4 March 2012.

Accepted for publication: 5 March 2012.

This work is licensed under a Creative Commons Attribution NonCommercial 3.0 License (CC BYNC 3.0).

(O) Copyright B. Keikhaei et al., 2012

Licensee PAGEPress, Italy

Hematology Reports 2012; 4:e7

doi:10.4081/hr.2012.e7

untransfused patients with thalassemia intermedia and less commonly in inadequately transfused $\beta$-TM patients when erythropoiesis is not suppressed adequately by transfusions. ${ }^{9}$ The incidence of EMH in patients with thalassemia intermedia may reach up to $20 \%$ compared to TM patients where the incidence is less than $1 \%{ }^{1}$ The most common site involved by $\mathrm{EMH}$ in thalassemia patients is spinal column particularly thoracic region. The reason for the increased frequency of EMH around the spinal column, and more specifically at the thoracic levels, is unknown. EMH has been reported nearly in every organ, but is frequently seen in hepatosplenic areas which can potentially produce fetal hemoglobin. Non hepatosplenic EMH has been reported in numerous sites, including lungs, gastrointestinal tract, urinary tract, adrenal glands, prostate, peritoneum, skin, breast, central nervous system and paravertebral areas. ${ }^{5,10-12}$

Adrenal gland EMH is extremely rare. One case in a patient with thalassemia intermediate has been reported by Chuang CK et al. ${ }^{13}$ The precise pathway of EMH involvement of the adrenal gland is unknown, but it is hypothesized that the adrenal gland has hematopoietic capacity in the fetus and EMH may originate from primitive rests. Other experts believe that adrenal gland involvement may result from embolization of hematopoietic stem cells. It might likely result from extrusion of bone marrow from nearby bone in the presence of bony erosions or fractures. ${ }^{13,14}$

The symptoms of EMH are site-specific- 


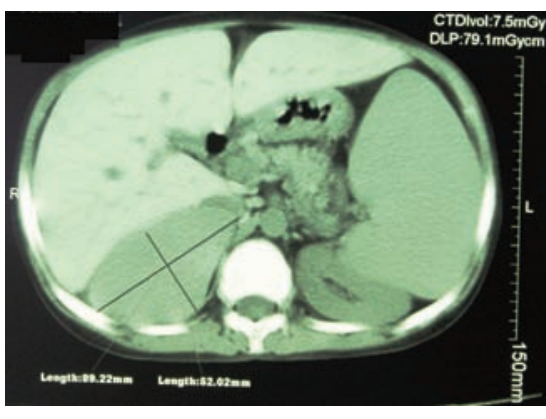

Figure 1. Right supra renal mass.

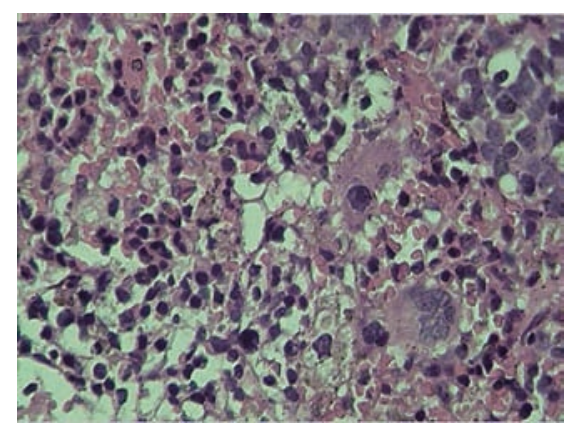

Figure 2. Depicts the adrenal cortical tissue with multiple foci of hematopoietic cells infiltration including erythromyeoloid, megakaryocytic cells and hemosiderin deposit.

related. Most EMH is asymptomatic and are discovered incidentally. Symptomatic EMH is due to mass effect upon the adjacent organs such as spinal column. Most EMH cases reported in literature were associated with thalassemia intermediate; whereas, the frequency in thalassemia major is very low, particularly, when erythropoiesis was not suppressed adequately by transfusion. ${ }^{9}$ In thalassemia major patients the treatment protocol to keep the pre-transfusion hemoglobin more than $9.5 \mathrm{~g} / \mathrm{dL}$ can support to supress ineffective erythropoiesis and the occurrence of EMH might be prevented. ${ }^{15}$ One presumptive cause of EMH is chronic hypoxia. In infrequent transfusion condition, such as the present case, blood transfusion cannot supress the chronic hypoxia and the occurrence of EMH as well.

Specific treatment may not be required unless EMH is accompanied by symptoms. Treatment options for thalassemia patients with EMH depend on the location and mass effect symptom and include surgery, radiation, blood transfusion and hydroxyurea or various combinations thereof. Excellent results have been reported in spinal cord compression due to $\mathrm{EMH}$ in thalassemia with radiotherapy alone. ${ }^{12,16}$
Hydroxyurea, besides stimulating the synthesis of hemoglobin $\mathrm{F}$ might play an active role in inactivation and even shrinking of the EMH. Hydroxyurea increases hemoglobin $\mathrm{F}$ levels and improves the effectiveness of erythropoiesis in $\beta$-thalassemia diseases. ${ }^{17,18}$

Blood transfusion with the favourable effect on the ineffective erythropoiesis suppression may shrink EMH in thalassemia. Combination of transfusion and hydroxyurea can be recommended in some thalassemia cases with EMH. ${ }^{19}$ Surgical operation can be indicated in radiation failure cases as the procedure cannot control the EMH symptoms. ${ }^{20}$ Our patient did not accept the recommended treatment of surgery and/or radiotherapy. The patient was advised to follow treatment for 6 months. Until now (2 months after diagnosis), the patient is well and the prehemoglobin level is more than $9.5 \mathrm{~g} / \mathrm{dL}$. Follow up imaging will be done after 6 months.

The presence of hepatosplenomegaly in our patient showed a sign of hepatosplenic EMH. The chance of nonhepatosplenic EMH is low in the presence of hepatosplenomegaly. The presence of spleen has an active role in prevention of non hepatosplenic EMH. Spleen has a filtration role in spreading of hematopoietic stem cell. Contrary to this idea, our patient had a huge spleen. It indirectly indicates the poor management of index patient and shows the intensity of forces of ineffective erythropoiesis. ${ }^{21}$ Non previous splenectomy in third decades is another clue for poor patient's management. The patient had also no good compliance to deferoxamine injection.

There have been several case reports of thalassemia intermediate with EMH published in the literature and only rare cases presented with adrenal EMH. ${ }^{13}$ We present a case report of adrenal gland EMH with thalassemia major. We could not find any similar case reported in the medical literature, and we think that our case report may be the first of its kind to be published.

\section{Conclusions}

This report describes the case of a patient with thalassemia major who was found incidentally a supra adrenal mass at Ultrasonography. EMH should be considered in the differential diagnosis of any patient with thalassemia intermediate and major who presents with a solitary mass. The patient did not have a good management on his life. The presence of hepatosplenic and non hepatosplenic EMH show the poor management of patient. The diagnosis was established on the basis of CT scan and histopathology. The publication of this article may raise the clinician's awareness of the diagnosis and treatment of thalassemia with EMH.

\section{References}

1. Taher A, Ismaeel H, Cappellini M. Thalassaemia intermedia:revisited. Blood Cells Mol Dis 2006;37:12-20.

2. Keikhaei B, Zandian K, Rahim F. Existence of cord compression in extramedullary hematopoiesis due to beta thalassemia intermedia. Hematology 2008;13:183-6.

3. Stamataki S, Behar P, Brodsky L. Extramedullary hematopoiesis in the maxillary sinus. Int J Pediatr Otorhinolaryngol Extra 2009;4:32-5.

4. Gogia P, Goel R, Nayar S. Extramedullary paraspinal hematopoiesis in hereditary spherocytosis. Ann Thorac Med 2008;3:64-6.

5. Horwood E, Dowson H, Gupta R, et al. Myelofibrosis presenting as spinal cord compression. J Clin Pathol 2003;56:154-6.

6. Rice GPA, Assis LJP, Barr RM, et al. Extramedullary hematopoiesis and spinal cord compression complicating polycythemia rubra vera. Ann Neurol 1980;7:81-4.

7. Choi H, David CL, Katz RL, et al. Case 69: extramedullary hematopoiesis1. Radiol 2004;231:52-6.

8. Ahuja S, Grover G, Jha AK, et al. Extramedullary hematopoiesis presented as solitary renal mass: A case report with review of literature. Diagnostic Cytopathology 2011;39:435-7.

9. Korsten J, Grossman H, Winchester P, et al. Extramedullary hematopoiesis in patients with thalassemia anemia. Radiology 1970;95:257-63.

10. Papavasiliou C. Clinical expressions of the expansion of the bone marrow in the chronic anemias: The role of radiotherapy. Int J Radiat Oncol, Biol, Phys 1994;28:60512.

11. Georgiades CS, Neyman EG, Francis IR, et al. Typical and Atypical Presentations of Extramedullary Hemopoiesis. Am J Roentgenol 2002;179:1239-43.

12. Papavasiliou C, Sandilos P. Effect of radiotherapy on symptoms due to heterotopic marrow in beta-thalassemia. The Lancet 1987;329:13-4.

13. Chuang C, Chu S, Fang J, et al. Adrenal extramedullary hematopoietic tumor in a patient with beta-thalassemia. J Formos Med Assoc 1998;97:431-3.

14. Chourmouzi D, Pistevou-Gompaki K, Plataniotis G, et al. MRI findings of extramedullary haemopoiesis. Eur Radiol 2001; 11:1803-6.

15. Wyatt JP, Sommers SC. Chronic marrow failure, myelosclerosis and extramedullary hematopoiesis. Blood 1950;5:329-47.

16. Munn RK, Kramer CA, Arnold SM. Spinal cord compression due to extramedullary hematopoiesis in beta-thalassemia inter- 
media. Int J Radiat Oncol Biol Phys 1998;42:607-9.

17. Hoppe C, Vichinsky E, Lewis B, et al. Hydroxyurea and sodium phenylbutyrate therapy in thalassemia intermedia. Am J Hematol 1999;62:221-7.

18. Cario HC, Wegener MW, Debatin KMD, et al. Treatment with hydroxyurea in thalassemia intermedia with paravertebral pseudotumors of extramedullary hematopoiesis. Ann Hematol 2002;81:478-82.

19. Chehal A, Aoun E, Koussa S, et al. Hypertransfusion: a successful method of treatment in thalassemia intermedia patients with spinal cord compression secondary to extramedullary hematopoiesis. Spine 2003;28:E245-E9.

20. Niggemann P, Krings T, Hans F, et al.
Fifteen-year follow-up of a patient with beta thalassaemia and extramedullary haematopoietic tissue compressing the spinal cord. Neuroradiol 2005;47:263-6.

21. Wolf BC, Neiman RS. Hypothesis: splenic filtration and the pathogenesis of extramedullary hematopoiesis in agnogenic myeloid metaplasia. Hematol pathol 1987;1:77-80. 